\title{
Jorge Andrade, a História e o teatro paulista: um momento de renovação
}

Aparecido José Carlos NAZÁRIO ${ }^{1}$

Universidade Estadual de Campinas - Unicamp

Os noventa anos de nascimento de Jorge Andrade nos remetem à reflexão acerca da importância desse notável dramaturgo que deixou, em termos de qualidade, uma herança apreciável para o teatro brasileiro. Calcado na memória individual e mesmo coletiva, a obra do dramaturgo se sustenta não apenas pelo ciclo desenvolvido em Marta, a árvore e o relógio, mas também pela sua contribuição após a década de setenta (inclusive na televisão), demonstrando que em veículos de comunicação diferenciados também poderia ser feito um trabalho de cunho social e de elevado questionamento, como por exemplo na teledramaturgia. Em estudos recentes, em que sociólogos como Maria Arminda do Nascimento Arruda (2001) e antropólogos como Heloísa Pontes (2010) se debruçam detalhadamente a respeito da produção cultural da cidade de São Paulo, não dá para descartar a presença de Jorge Andrade na composição da metrópole.

Maria Arminda do Nascimento Arruda propõe um estudo sobre Jorge Andrade enquadrando-o como um dos grandes nomes do teatro brasileiro que, juntamente com outras personalidades do porte de Florestan Fernandes (objeto de estudos da autora na mesma obra), constituem-se nos responsáveis pela consolidação de um estilo próprio que definem a metrópole paulista a partir da década de cinquenta. Já Heloísa Pontes, lançando mão de um olhar diferenciador, destaca a relevância de atores, críticos, diretores e atrizes na construção da fisionomia cultural paulista nas décadas de quarenta, cinquenta e sessenta, denominando-os “intérpretes da metrópole”. Embora não haja na referida obra um estudo que evidencie a contribuição de Jorge Andrade (certamente por questões de recorte e direcionamento da temática), é indiscutível que no panorama apresentado pela autora ele se mostra atuante mesmo por trás das cortinas, perpassando a história do teatro paulista e se misturando ao universo de composição da dramaturgia.

Nesse sentido, tendo em vista que o teatro paulista é rico na proliferação de profissionais que refletem sobre a formação da metrópole, é bem oportuna a lembrança de Jorge Andrade se levarmos em consideração dois aspectos importantes que serão discutidos: 1) a contribuição social do teatro de Jorge Andrade e sua relação com a

\footnotetext{
${ }^{1}$ Bacharel em Letras pela UNICAMP, Mestre em Letras na área de Teoria Literária do Instituto de Estudos da Linguagem da mesma Instituição e Doutor em Letras pelo Departamento de Teoria Literária e Literatura Comparada da USP. É professor do curso de Letras da FESB (Fundação Municipal de Ensino Superior de Bragança Paulista)e Pós-doutorando do IEL/UNICAMP. E-mail: nazariobr@terra.com.br.
} 
História; 2) o respeito que o autor sempre despertou na crítica e nos historiadores do teatro de maneira geral. Comecemos pelos estudiosos.

Os historiadores do teatro moderno nos mostram que alguns autores se destacaram na tarefa de impor um novo ritmo de trabalho à pesquisa e à composição teatral. Analisando o período posterior a 1930, podemos notar que uma nova era dramática estava surgindo no Brasil. Grandes companhias se organizavam com o objetivo pleno de formar bons atores capazes de representar, de modo consciente, a realidade em que viviam. Além disso, a própria profissão de ator começava a ser vista como atividade técnica que precisava de aprimoramento com o estudo, os exercícios e a devida aplicação. Esse momento especial, que marca, inclusive, o aparecimento de Jorge Andrade na cena paulista, é detectado também por sociólogos do pote de Maria Arminda do Nascimento Arruda que, ao refletir sobre a metrópole paulista em momentos significativos no século $\mathrm{XX}$, não deixa de lado a contribuição do dramaturgo, não deixando também de lado um seleto grupo de autores que definiram a arte do espetáculo nas primeiras décadas. Segundo a autora (ARRUDA, 2001, p. 135):

No meio do século XX, o teatro de São Paulo celebra a sua estreia no cenário das linguagens modernas. Diferentemente da ficção, da poesia, mesmo do ensaísmo, que haviam assentado as bases da renovação expressiva há pelo menos trinta anos, o gênero teatral parecia sofrer de uma espécie de paralisia, a despeito de existirem peças escritas pelos próprios modernistas. O tempo de espera terminaria com o aparecimento das casas de espetáculos. Um novo teatro nascia na capital...

Além de Jorge Andrade, um dos nomes mais representativos nesse novo panorama é Alfredo Mesquita (o fundador da Escola de Arte Dramática, em São Paulo), o qual teve grande importância na formação de uma nova concepção de teatro no Brasil. Dramaturgo de inestimável valor intelectual, Alfredo Mesquita trabalhou de perto com o tema da decadência da aristocracia rural, a que se filia a temática de Jorge Andrade. Através de suas peças, ele estuda, particularmente, as causas da desintegração da família tradicional paulista. Com a crise cafeeira de 1929 e a revolução de 1930, tais famílias eram obrigadas a assumir uma nova postura. Sua peça mais representativa é Em família (1936), obra na qual ele mostra o comportamento dos vitimados pela crise do café, sendo obrigados a deixar suas fazendas e bens. Dentro desse contexto, enquadramos a figura de Jorge Andrade, uma vez que este, ingressante na Escola de Arte Dramática, aprenderia lá com professores como Décio de Almeida Prado e Alfredo Mesquita a técnica necessária (e até mesmo adequada) para ser um escritor bem sucedido. Juntamente com o objetivo da EAD ao apostar na formação de bons atores, residia também o desejo de formar dramaturgos, diretores 
competentes, encenadores especializados e qualquer profissional que se enquadrasse numa proposta diferenciada de uma dramaturgia de qualidade. Nesse meio, Jorge Andrade aprendeu os primeiros passos da escrita e ainda na EAD escreveu sua primeira peça $(O$ telescópio) intitulada na época As colunas do templo.

Ao sair da EAD, o recém-dramaturgo começa sua intensa carreira profissional. Sua primeira peça de êxito seria $A$ moratória, trabalho de peso na dramaturgia nacional que marcaria toda uma época. A partir desse instante, Jorge Andrade passaria a despertar o interesse da crítica por apresentar um teatro extremamente bem cuidado e orientado. Ele aparecia num momento em que havia uma carência de bons autores, instaurando, assim, a renovação a seu modo, já que inaugurava um tema inédito e abria caminho para uma linguagem teatral diferenciada.

Através da reflexão de alguns estudiosos, podemos entender melhor a relação do teatro de Jorge Andrade com seu contexto social e sua realidade cultural. Começando por Sábato Magaldi, depreendemos, através de seu livro Panorama do teatro brasileiro (1962), toda a atmosfera cultural que pairava no período e como os principais dramaturgos eram vistos e caracterizados pela crítica. Encontramos, na respectiva obra, uma visão nítida acerca da influência de nosso dramaturgo naquele contexto cultural, como também das influências que recebeu de outros grandes intelectuais. Juntamente com alguns nomes de peso como Nelson Rodrigues, Gianfrancesco Guarnieri e Ariano Suassuna, Jorge Andrade contribuiu para que o teatro nacional tivesse obras de porte singulares pelo caráter de reflexão, capazes de fazer com que a dramaturgia brasileira fosse reconhecida devido à qualidade, demonstrando, através de bons textos, seus próprios temas e inquietações.

Partindo dessas características, Sábato Magaldi relata as qualidades de Jorge Andrade, que teria modificado o teatro brasileiro com sua peça $A$ moratória em 1955. Ele teria inaugurado uma nova linguagem, recebendo, segundo o crítico, influências de dramaturgos da mais alta categoria como Nelson Rodrigues, este com repercussão inegável no plano da memória, da manipulação temporal, da linguagem seca e telegráfica (semelhante à dos expressionistas). Sendo assim, Vestido de noiva (que também teria sido um marco no teatro brasileiro na década de 40) teria exercido uma influência marcante sobre Jorge Andrade no sentido de devolver na década de 50 o lugar que a cultura brasileira havia perdido nos anos passados. Nesse sentido, podemos verificar os vários aspectos da contribuição de Jorge Andrade no momento de sua produção. Alguns deles podem ser averiguados aqui na exposição que apresentaremos, tendo como pauta a inauguração de um novo tema e a contribuição conjunta com outros autores. 
Nosso ponto de referência é ainda o crítico Sábato Magaldi (Idem, p. 216). Para tecer sua argumentação, ele afirma acerca da peça escrita por Jorge Andrade:

A leitura de Vestido de noiva deu-lhe a pista da nova dialogação que passaria a cultivar: frases secas, cortantes, incisivas - um pingue-pongue contínuo em que a palavra ressoa em plenitude ao ser explanado no palco. Também o abandono da continuidade rígida no tempo, já experimentado na peça de Nelson Rodrigues, e a profunda admiração por $A$ morte dum caixeiro viajante, de Arthur Muller, sugeriram as primeiras linhas sobre as quais pôde desenvolver a arquitetura de $A$ moratória.

Também podemos ver nesse mesmo livro a comparação que Sábato Magaldi (Idem, p. 239) faz entre Jorge Andrade e demais intelectuais daquele panorama cultural: "Nelson Rodrigues, Jorge Andrade, Ariano Suassuna e Gianfrancesco Guarnieri trouxeram, a nosso ver, até o momento, as contribuições mais efetivas e continuadas à dramaturgia brasileira contemporânea". Desse modo, depreendemos a relevância de Jorge Andrade para o teatro em questão, caracterizando-se como um dos autores mais significativos do período. Em relação a outros autores, ele se destacou como um dos grandes ícones do teatro nacional, uma vez que, após Nelson Rodrigues, dramaturgo que propunha uma leitura diferenciada da sociedade, optando por abrir-lhe as feridas pela denúncia de sua hipocrisia, o teatro brasileiro estava carente de bons autores que expressassem realmente um conteúdo de caráter nacional. Mesmo com o surgimento de grandes companhias, como por exemplo $O s$ Comediantes, que propunham uma linguagem teatral diferenciada, apoiando-se na direção de Ziembinski, havia uma lacuna que desde a década de 40 precisava ser preenchida.

Tomando como ponto de partida o momento de transformações experimentado pelo teatro brasileiro, não desconsideramos, com isso, as manifestações artísticas anteriores, como por exemplo a de Álvaro Moreyra, que, no Modernismo brasileiro, contribuiu com encanto e fascínio no campo das artes cênicas através de seu Teatro de Brinquedo. Enfatizamos, apenas, que nos primeiros séculos ainda caminhávamos para a formação de um teatro nacional, abrindo caminho para manifestações artísticas futuras que encontrariam o devido respaldo em tais produções. No que diz respeito às incursões nacionais, João Roberto Faria (1998, p. 112) afirma:

(...) Álvaro Moreyra merece ser lembrado em nossa história teatral. Sua peça e o Teatro de Brinquedo são iniciativas louváveis e demonstram, nos anos 20, que os ventos da renovação modernista atingiram o teatro, mas que também não era fácil quebrar com a resistência das velhas formas.

Retomando a discussão acerca da contribuição de Jorge Andrade, pode-se ressaltar que nesse período de transformações, que coincide com a aparição do dramaturgo, um 
importante empreendimento paulista surgiu. Foi a criação do TBC (Teatro Brasileiro de Comédia) através do empresário Franco Zampari. Este importante teatro paulista revelou grandes nomes da dramaturgia nacional, entre atores, diretores e dramaturgos. Durante as fases de sua existência (1948-1964), o referido teatro passou por fases distintas, sobrevivendo, em meio a dívidas e períodos de derrocada, tendo seu fechamento decisivo no ano de 1964. Durante a trajetória do TBC, a contribuição de Jorge Andrade foi significativa na manutenção do teatro, principalmente na década de sessenta. Duas das peças de Jorge Andrade de maior sucesso foram encenadas no TBC ( $A$ escada e Os ossos do Barão) e conseguiram permanecer um bom tempo em cartaz. Além do espaço concedido a Jorge Andrade, autores nacionais como Dias Gomes e Gianfrancesco Guarnieri (além de Abílio Pereira de Almeida que já na primeira fase do teatro marcava presença com suas comédias) encenaram peças no TBC, atendendo, na época, a necessidade de se colocar em cena questões nacionais que mostravam a face do brasileiro e refletiam um pouco de nossa identidade. Com isso, acreditava-se que especialmente os autores paulistas conseguissem alavancar peças significativas que revelassem, através dos temas que propunham a identificação com a sociedade, um pouco da nossa brasilidade. No entanto, as expectativas foram frustradas. Apesar de todos os esforços, esse teatro não dispensou os autores estrangeiros e quase não havia espaço para os autores brasileiros. As companhias estrangeiras tinham a maioria das oportunidades e prevalecia a necessidade de bons espetáculos nacionais.

Nesse emaranhado de surpreendentes acontecimentos, tendo ainda em mente o destaque de Jorge Andrade no teatro paulista, não podemos deixar de mencionar, ao falarmos do TBC, de um autor que, ao contrário de vários, teve uma inegável repercussão nesse espaço cultural: Abílio Pereira de Almeida². Contemporâneo de Jorge Andrade, esse dramaturgo encantava pela habilidade que possuía na construção de diálogos e agilidade para criar tipos engraçados. O TBC foi seu grande campo de atuação, embora tenha também se desenvolvido como cineasta e jornalista. De igual modo, Abílio também pertencia a uma elite e retratava em suas peças temas semelhantes a Jorge Andrade, como por exemplo a questão da terra e da tradição através das oligarquias.

\footnotetext{
2 Abílio Pereira de Almeida foi objeto de estudo de nossa tese de doutorado intitulada Descontinuidade $e$ literatura: historicidade de São Paulo na ótica de Abílio Pereira de Almeida. No referido trabalho, procuramos entender como a visão do intelectual acerca da história de São Paulo se mostrava diversificada ao longo de três décadas, procurando verificar também que nos diferentes gêneros experimentados pelo intelectual (narrativa, teatro e cinema), uma parte distinta da história paulista era tematizada. A trajetória de Abílio se tornou mais desafiadora pelo fato de no mestrado nos dedicarmos ao estudo da obra de Jorge Andrade (Tempo e memória no teatro de Jorge Andrade: uma leitura de Rasto atrás) que, assim como Abílio, também se ateve, com olhar diferenciado, a um certo segmento da sociedade paulista, tendo sido, por conta disso, considerado o dramaturgo de São Paulo.
} 
É nesse contexto que podemos precisar mais de perto a relevância de Jorge Andrade em comparação a outros autores. O que podemos dizer de Abílio Pereira de Almeida é que este capta com muita meticulosidade, através dos diálogos construídos, um momento de contradição da burguesia paulista. O movimento que Jorge Andrade descreve na zona rural é semelhante ao que Abílio retrata na cidade. Com muita destreza, ele revela ao leitor elementos escusos no cotidiano do paulista conservador. Temas como a prostituição, a ascensão da classe média, a mediocridade e o marasmo da sociedade, entre outros, são colocadas de maneira dinâmica em suas peças. Através delas, podemos ter um retrato, muitas vezes exagerado, das principais figuras que compunham a terra paulista nas décadas de 40 e 50.

Uma das análises mais bem aprofundadas do teatro de Abílio Pereira de Almeida pode ser encontrada no estudo de uma de suas peças. Nesse livro, escrito por Gilda de Mello e Souza, temos acesso ao ensaio intitulado Teatro ao sul. A autora faz uma análise comparativa entre a peça Santa Marta Fabril S.A. de Abílio Pereira de Almeida e A moratória de Jorge Andrade. Através dessa comparação, ela garante à peça de Jorge Andrade a importância que lhe é peculiar:

Mas se Santa Marta Fabril inventa principalmente um tipo, $A$ moratória descobre sobretudo um tema, abrindo para a literatura teatral do sul uma nova era. $\mathrm{Na}$ verdade, representa para o novo meio o que os romances de Lins do Rego representam para o Nordeste: a descoberta de um riquíssimo filão literário, o drama do café (MELLO E SOUZA, 1986, p. 89).

Historicamente, podemos comprovar o papel desempenhado por Jorge Andrade dentro de uma época carente de bons autores. O compromisso com o momento histórico é bem visível se levarmos em consideração o enredo de suas peças e a forte ligação que elas tinham com a História brasileira, tentando, por exemplo, retratar a realidade com uma profundidade que levava à crítica social, fazendo com que o homem tivesse consciência de seu passado e de sua função dentro de um mundo novo repleto de desafios. Era uma nova temática que nascia no teatro brasileiro, mostrando as tensões sociais e os dramas que existiam por trás da máscara da tradição.

Por esse compromisso com a História e por esse novo tema instaurado, podemos verificar a importância de Jorge Andrade na caracterização de um período e na compreensão do mesmo através de personagens significativos. A preocupação com o momento histórico de forma mais intensa diferenciava o intelectual de outros autores como Abílio Pereira de Almeida e o colocava num patamar de questionamento que elevava seu teatro para um caráter social em falta no país, conferindo à obra de Jorge Andrade um 
tom diferenciador. Esse questionamento mostra-se necessário quando se trata de considerações acerca do teatro andradino, uma vez que sempre que aparece um movimento novo existe uma tendência em enquadrá-lo dentro de uma categoria de engajamento. Em especial no teatro, existe uma cobrança em encerrá-lo dentro de um clichê político, social ou mesmo épico. No caso de Jorge Andrade, temos uma grande tendência em caracterizálo como teatro épico, principalmente se levarmos em conta a sua produção final, através das peças As confrarias e $O$ sumidouro. No entanto, qualquer classificação assumida de maneira definitiva foge à totalidade dos objetivos de Jorge Andrade, mesmo que admitamos o valor social que o dramaturgo tinha em mente, conseguindo, em variadas peças, marcar a fundo o tom de crítica a determinado segmento da sociedade. Mesmo assim, vale a pena abordarmos algumas classificações que fizeram parte dos estudos teatrais em momentos diversificados.

Quem discute essas questões de forma bem abrangente é Sábato Magaldi. A preocupação do enquadramento é tão intensa que mereceu pelo menos, por parte da crítica, uma leve explanação. Em seu livro Iniciação ao teatro (1986), ele apresenta tais questões e tenta dar um perfil de cada tipo de teatro e a propriedade de cada um, dandonos uma visão geral do texto e do espetáculo. No capítulo 11, por exemplo, intitulado Qualificativos em voga, Sábato Magaldi discute as diferenças entre teatro épico (segundo a concepção teórica de Brecht), teatro social (que tem por objetivo inserir o homem no seu papel social, tendo sempre um elemento condutor através da História) e teatro político (em que a linha mestra é a luta de classes). Apontando as divergências que existem em decorrência de cada classificação, Magaldi nos apresenta os principais problemas que podem ocorrer dentro dessas três visões, muitas vezes atacadas (enquanto forma de atacar o papel do teatro como arte) por diversos dramaturgos. O risco que corremos em adotar determinada classificação para a dramaturgia de um dado autor é rotulá-lo simplesmente como produtor de um tipo específico de cultura, desejando inseri-lo dentro de um contexto que pode não ser o seu. Nesse caso, por exemplo, podemos cometer a impropriedade de classificar um autor como representante de um teatro social e descartar a possibilidade de vê-lo como representante de uma atividade política. No entanto, os textos desse autor, mesmo que não assumam engajadamente a luta de classes, podem ter um teor político muito mais presente do que aqueles que defendem de modo intenso esse tipo de comportamento. O mesmo pode acontecer com um texto teatral que não trabalha abertamente com o teatro épico de Brecht, apesar de trazer em sua escrita marcas que revelam características narrativas. Lutar por uma classificação pura é o mesmo que 
defender a ideia de que um autor não é influenciado por forças exteriores a ele, negando, assim, a força de um contexto de época. Mesmo quando um escritor não demonstra claramente em seu trabalho inquietações de sua época, ele pode estar se sentindo incomodado com a atitude de um certo segmento social e transmitir em sua produção uma visão mais camuflada, diferente dos grupos abertamente engajados.

Por tudo isso, entendemos a preocupação de Sábato Magaldi ao apresentar esses três tipos de classificação e propor o significado de cada uma delas. O que mais nos interessou nessa apresentação é o tipo de teatro no qual Jorge Andrade se enquadraria. De acordo com o perfil apresentado pela obra andradina, denotamos que o teatro social é uma das classificações mis adequadas, devido ao fato de existir uma ligação, nesse tipo de teatro, com um elo histórico. Sabemos que a relação de Jorge Andrade com a História é de grande significado, bem expressa em peças como A moratória, Pedreira das almas, As confrarias, $O$ sumidouro etc. A respeito dessa relação do dramaturgo com a História de seu país, Catarina Sant'Anna assinala (1997, p. 218):

Acreditando encarnar em suas peças uma visão histórica (...), Jorge Andrade, quando acusado pela cobrança de uma posição ideológica em seu trabalho, aponta o uso que faz da História no teatro como elemento suficiente para atestar sua condição de artista "político": "Escrevendo sobre a História de meu país, tentando registrar o homem brasileiro no seu tempo e no seu espaço, eu estou sendo político".

Seguindo ainda nessa direção, sabemos também da preocupação social desse autor retratada em peças como Vereda da salvação, A zebra e Milagre na cela. Essas duas últimas peças mostram um Jorge Andrade preocupado com uma nova vertente do segmento social. Trata-se de uma fase posterior àquela do ciclo, em que assuntos como a cegueira proporcionada pelo futebol enquanto objeto de enriquecimento através das loterias são retratados de outra maneira, a fim de despertar a conscientização e propiciar um momento de reflexão sobre os acontecimentos que estavam presentes no país, mas que não incomodavam a grande massa, acomodada em seu lugar aconchegante e sem nenhuma preocupação com o que se passava a seu redor, dando vazão à ilusão das loterias de futebol e à torcida por um time, na dependência de um empate ou uma vitória para ter direito a um prêmio. Nesse caso, Jorge Andrade cumpre um papel social e faz com que questões desagradáveis sejam colocadas à prova através da encenação, tendo em vista as perspectivas de uma mudança. Esse caráter de denúncia faz do teatro andradino um representante do elemento social, juntamente com o valor histórico e político bem dosados. Sendo assim, a combinação das várias visões que confluem tanto para o político como para o social, 
valorizando o elemento humano e sua posição na sociedade, nos parecem preponderantes e sustentáveis no conjunto da dramaturgia.

Esse trabalho humano, alvo das preocupações na arte do dramaturgo, pode ser bem exemplificado através da peça Milagre na cela. Nesta peça, totalmente diferenciada das anteriores presentes no ciclo, nota-se a preocupação do dramaturgo em discutir uma questão atual e não atrelada ao passado, lançando mão de uma certa memória política para explicar o presente. Nesse instante é um novo ciclo que se apresenta e a preocupação é expor uma situação de horror que perturba a sociedade, embora esta não se sinta com forças para mudá-la. Entretanto, a função do dramaturgo era denunciar sem abrir mão da História presente que estava bem à vista, expressa nas palavras e nas atitudes de uma freira torturada na ditadura militar devido ao seu intenso envolvimento com atividades políticas. Nesse contexto social, Jorge Andrade procurou retratar tanto a realidade do torturador como a do torturado, procurando explicar as causas sociais e emocionais que poderiam unir as vertentes opostas de uma engrenagem social, desculpando até mesmo o fato de a vítima se envolver emocionalmente com seu algoz, a ponto de não questionar a possibilidade do envolvimento físico.

Pensando ainda na repercussão dessa peça na fase posterior do autor, a estudiosa Catarina Sant'Anna ressalta (p. 220), apoiada em comentários do próprio Jorge Andrade:

(...) Jorge Andrade fala sobre Milagre em 1977, defendendo a necessidade de registro daquela época difícil, para o que dizia sentir-se com liberdade e independência: "Não trato apenas de um fato histórico, conjuntural brasileiro, embora parta especificamente de acontecimentos, de dadas coisas, de fatos históricos brasileiros. Seu sentido, porém, é universal, em favor da liberdade, dos direitos do homem no mundo de hoje"; "Não é de modo algum uma peça partidária. (...) Eu falo do homem no seu sentido histórico. Seja ele um santo, seja um assassino. Seja fascista, seja comunista. Quero no teatro a presença desse homem, com toda a sua problemática, suas angústias, vivências, suas contradições" J.A., 15-06-1977).

Revelando as mazelas da sociedade, tanto na primeira como na segunda fase de sua produção, Jorge Andrade acharia seu verdadeiro papel na História. Retomando a primeira fase, sustentáculo de sua produção, nos parece plausível a ideia de que o caráter de denúncia adquirido por esse teatro se deveu ao fato da existência de um passado que foi devidamente enterrado. Além disso, toda uma vida foi colocada à prova dentro de um processo de sondagem do tempo. Por isso, reconhecemos um caráter social em Jorge Andrade que se manifesta já nos primeiros instantes de sua trajetória como dramaturgo e experimentador da História cafeeira paulista, podendo ser averiguado desde sua primeira 
peça de sucesso em 1955. O trabalho primoroso com a temporalidade já preconizava na época a preocupação em denunciar um momento histórico marcado pela contradição de uma aristocracia social. Através do elemento temporal, ele mostrava que a História tinha muito a nos ensinar, tendo em vista a tentativa de uma leitura minimamente correta dessa vertente histórica. Desse modo, o passado poderia se misturar ao presente num conflito que acabaria na perda de uma fazenda e numa esperança que só se manteria viva através do tempo, que num certo sentido mantinha uma característica atemporal. Sábato Magaldi, ao analisar a peça $A$ moratória, trabalha com a ideia de uma atemporalidade, intercruzando passado, presente e futuro:

A moratória só poderia lançar mão de dois planos - passado e presente - para traduzir a procura do autor. O passado, com a perda da fazenda, ainda não concluíra o retrato da família e era necessário, assim, pintá-la na vida medíocre da cidade, tentando em vão recuperar as posses antigas. As ideias e os movimentos das personagens, não se adaptaram às novas condições de existência e, para enunciar a constante psicológica, o texto joga com uma certa atemporalidade: sugere-se um conflito no presente e ele será desenvolvido no passado, como se fosse futuro, porque naquele mundo nada se altera de fato. (MAGALDI, 1962, p. 261)

Realmente, através dessa atemporalidade verifica-se o conflito que se estabelece e o grande entrave social a que os personagens estão condicionados. $O$ teatro de Jorge Andrade se reveste de todos os tipos de mascaramento que possam revelar em toda sua trajetória os desenlaces de uma sociedade tradicional. É através da leitura da tradição que essa dramaturgia começa a se sustentar na primeira fase, não percebendo que estabeleceria os subsídios para a dramaturgia futura. Talvez Jorge Andrade, ao escrever essas peças em momentos históricos distintos, nem tenha se conscientizado de que estava entrelaçando a sua própria história de vida. O tempo foi o indicador disso e revelou a tradição entranhada nele como um ingrediente indispensável em seu teatro. Essa marca, sem dúvida, seguiria Jorge Andrade por toda a vida e se manteria viva em suas peças, fossem elas as mais diferenciadas possíveis.

Nesse sentido, podemos ver como o teatro de Jorge Andrade apresentou uma relevância na década de 50 através desses questionamentos. Hoje em dia, esse teatro também é reconhecido através das montagens que são e já foram realizadas em décadas recentes, como as do grupo TAPA e a de Antunes Filho, provando que existe, ainda hoje, a possibilidade de entender a História através de uma peça de Jorge Andrade. Atualmente, 
seu valor é reconhecido e inegavelmente seus textos portadores de qualidade e refinada reflexão. Vejamos, por exemplo, o que diz Fernanda Montenegro ${ }^{3}$ :

A dramaturgia de Jorge Andrade teve, para a década de 50, um papel similar ao de $V$ estido de noiva na década de 40. Ela antecedeu em forma e concepção o papel que depois seria exercido pelo Teatro de Arena. Dizer-se, como muitos fizeram, que ele era um autor conservador, voltado para a aristocracia, o amargurou demais, porque não é verdade, é mera leviandade, que só se explica por disputa no plano ideológico. Afinal, ele era um autor essencialmente progressista.

Ainda nos dias de hoje, podemos ver que esse teatro é reconhecido como um elemento formador da cultura brasileira. Temos que reconhecer, dessa forma, o grande papel renovador que essa dramaturgia representou na época e representa atualmente, pois, com vias no passado, procurou fundamentar o presente, encontrando ainda ecos na atualidade e se sustentando através do compromisso com o social, mesmo enfrentando dificuldades.

Quando falamos em dificuldades, não podemos deixar de mencionar todos os tipos de problemas que Jorge Andrade enfrentou por ser um escritor requintado. Talvez a elegância de sua escrita tenha contribuído para que ele fosse tão desconsiderado dentro de uma sociedade que exigia tão pouco desse teatro. Num balanço atual, reconhece-se que na maioria das vezes sua obra foi incompreendida e, por isso, muitas de suas peças não foram encenadas. Esse trauma em sua vida se prolongou mesmo quando ele foi para a televisão. Por um lado, foi criticado por deixar o meio teatral e aderir a um veículo de comunicação tido como menor; por outro, seu texto na tv era considerado bom demais para uma proposta de comunicação tão comercial. Os últimos depoimentos sobre Jorge Andrade constatam que ele teve muitos desgostos na televisão. Sua produção não era valorizada e em decorrência disso seu estado emocional teria se agravado. Contudo, já nas décadas passadas, mesmo no teatro, ele já sofria represálias e os limites econômicos impediam que fosse realizado um trabalho compatível com o nível desejado. Quem pode nos dar uma informação precisa sobre o início da trajetória de Jorge Andrade é Gianfrancesco Guarnieri ${ }^{4}$ :

Foi difícil para Jorge Andrade conviver com as limitações econômicas do teatro brasileiro, que exigiam textos para poucos atores. Ele tinha tamanho rigor que não queria nem levar em conta os problemas de produção. Quando eu era ainda líder estudantil, fui assistir à sua peça $A$ moratória, que acabou me motivando para escrever Eles não usam Black-tie. Em 58, depois da montagem dessa minha peça,

\footnotetext{
${ }^{3}$ Essa declaração de Fernanda Montenegro se encontra na revista do SESC (p. 32) referente à programação da peça Vereda da salvação encenada por Antunes Filho em dezembro/1993 a meados de 1994. Além de declarações, contém também vários estudos sobre o dramaturgo.

${ }^{4}$ Idem nota anterior.
} 
Jorge, com quem sempre mantive contato, veio me dizer que ela acabara se transformando na força impulsora para ele continuar escrevendo.

É através desse rigor que o teatro de Jorge Andrade pode ser caracterizado. Como diz Fernanda Montenegro, ele antecipou todo um momento de questionamento social que seria continuado pelo Teatro de Arena. Sem dúvida, ele inspirou uma época através de seu modo fragmentário ao se colocar diante de uma realidade carente de interpretação. Esse teatro, hoje visivelmente reconhecido como um teatro que propõe uma volta "rasto atrás", pode ser analisado e colocado dentro de seu devido lugar ao ser avaliado pela crítica como um teatro que reúne qualidades dramáticas associadas às mais requintadas exigências cênicas. Jacó Guinsburg, ao refletir hoje sobre o teatro de Jorge Andrade, comprova que o rigor de sua escrita era um fator fundamental dentro da dramaturgia a que se propunha:

Jorge Andrade tinha o domínio da escritura teatral, dos procedimentos e da maquinaria cênica. Aliás, naquilo que lhe interessava, mostrou ser um virtuose. Basta ver as suas disposições cenográficas para o contraponto entre a realidade e a memória, magistralmente contrapostas para o jogo da interlocução não só verbal, como visual, e os seus flashes back, que não se limitam a operar dramatizações psicológicas, pois viabilizam também um certo metateatro e epicizações brechtianas (GUINSBURG, 1996, p. 115).

Ele também não se esquece de demonstrar como esse dramaturgo viveu num período que não comportava sua ambição e como seu porte de bom escritor era indesejado num mundo em que o bom nível teatral era ainda algo por descobrir. Talvez seu modo de ver a vida fosse um princípio que incomodava determinados segmentos sociais e, por causa disso, a arte que produzia era relegada a segundo plano. Dessa forma, Guinsburg nos apresenta um perfil de Jorge Andrade que chega a ser um retrato fiel de si mesmo enquanto escritor e, consequentemente, questionador da sociedade que o oprimia:

O seu pecado como dramaturgo foi, segundo certa óptica, o de ser um bom escritor, ou melhor, um grande escritor, cuja produção tem validade histórica além da primordial, é certo, que é a cênica. Por isso, em um teatro como o nosso, onde certos avanços ou modismos da linguagem cênica são feitos em detrimento de outras expressões não menos legítimas da cena, as suas peças passaram por um longo período de rejeição a título de literatura. Este fato foi a sua grande frustração. A falta de um teatro de repertório que encene constantemente o nosso acervo teatral, como ocorre em outros países, é, sem dúvida, um dos responsáveis por tal situação. Mas outra causa e, talvez mais ainda grave, é a concepção reinante, $\mathrm{e}$ às vezes redutora sobre que estilo e repertório de imagens falam efetivamente ao público de hoje, no Brasil. O teatro não é um palco de exclusões dogmáticas. Vanguarda e pesquisa de linguagem não excluem o texto do teatro nem o teatro de texto. Pois nada mais literário do que Shakespeare, Calderón, Molière ou Buchner, Tchekehov ou Pirandello que, no entanto, continuum sempre em cena, no teatro vivo. De modo que não há como questionar a existência de um espaço certo no tablado para uma obra e um autor do naipe de Jorge Andrade. E que assim o é, provou-o Antunes Filho. Primeiro por ter apresentado a potencialidade de Vereda 
da salvação em duas leituras diferentes. E não há dúvida de que a mais recente mostrou a força poética e dramática à luz da teatralidade de hoje, de Jorge Andrade. (Idem, ibidem)

Nesse sentido, Jorge Andrade experimentou o conflito social, na medida em que pagou por ser um bom escritor. No teatro suas obras não eram encenadas; na televisão, ele não contava com a liberdade de escrever um texto de nível mais elaborado. Dessa forma, ele ficou preso às contingências sociais, não podendo nem sequer desenvolver um trabalho adequado, uma vez que se sentiu perdido nos dois meios de comunicação, sendo obrigado também a deixar o veículo televisivo ${ }^{5}$. Talvez ele não visse nem mesmo a possibilidade de um retorno ao teatro, já que peças como As confrarias e $O$ sumidouro não teriam apoio para serem encenadas, devido ao alto custo que exigiam. Catarina Sant'Anna ressalta bem a qualidade dessas peças que, mesmo concebidas com rigor costumeiro do escritor, se tornariam incompatíveis com a condição econômica do teatro da época:

(...) pois, em que pese toda a carga de crítica social, política e cultural ali contida, vazada numa forma teatral dessacralizante, são obras assumidamente complexas e de encenação onerosa, construídas, como já mencionamos, sem a mínima esperança de que chegassem ao público, mas, e por isso mesmo, tão somente pelo puro prazer pessoal de continuar produzindo arte (SANT'ANNA, 1997, p. 298).

Dessa forma, temos exemplificado nele um escritor que pagou demasiadamente pelas ideias que transmitiu na produção do conjunto de sua obra. No entanto, culturalmente, ele representa para o teatro e para a literatura brasileira um momento de riqueza textual, no sentido de que seu teatro propõe uma infinitude de interpretações que são, através de cada peça, inesgotáveis e, num certo sentido, muito pouco exploradas. A capacidade de enxergar muito mais longe prova que é possível ainda, nos dias de hoje, deixar marcas e transmiti-las num contexto que pode permanecer, mesmo depois de muitas décadas, através do sistema e da História que se perpetua.

Partindo do princípio dessas considerações e retomando a reflexão de Heloísa Pontes, hoje, mais que nunca, podemos dizer que Jorge Andrade é um "intérprete da metrópole", contribuindo, ao lado de atores, diretores, encenadores e críticos de sua época com a fisionomia cultural da cidade de São Paulo. Sem a obra do dramaturgo, de certa forma, torna-se mais difícil, no campo da dramaturgia, a compreensão de nossa História,

\footnotetext{
${ }^{5}$ A proposta de dramaturgia de Jorge Andrade causava certa repulsa. Isso se dava porque seus textos eram muito bem cuidados. $\mathrm{O}$ autor se preocupava com a qualidade dramatúrgica e não somente com a produção televisiva de modo desqualificado. Esse tipo de comportamento o levou a ter problemas futuros, como por exemplo sua última novela na Rede Bandeirantes (Sabor de mel) em que o dramaturgo foi despedido antes do término da obra. Isso o amargurou muito, uma vez que na própria televisão conseguiu produzir trabalhos de alto nível como a novela Ninho da serpente, em que o problema da tradição e do apego às origens pôde ser retomado através de um outro veículo.
} 
uma vez que esta se mistura com a História paulista em variadas dimensões. Apoiado na leitura de todo um passado que se completa no ciclo paulista de Marta, a árvore e o relógio, bem como nas peças subsequentes, tendo em Milagre na cela uma das representantes vivas da ditadura militar, o dramaturgo revela a consciência de sua visão histórica ao passar por fases diferenciadas da História paulista, demonstrando, em momentos singulares (ao mesmo tempo em que é fiel à História de seu país), as descontinuidades desse processo, o qual teve seu panorama modificado num período de trinta anos de observação do dramaturgo. Nesse sentido, consideramos Jorge Andrade um grande leitor das transformações registradas na História paulista e no teatro brasileiro, colocando-o na categoria de intérprete da metrópole paulista, uma vez que ele (juntamente com diretores, atores e atrizes, que conferiram à cidade de São Paulo certa fisionomia no exato momento de suas respectivas atuações), captou analiticamente, com certa dose de precisão, as nuances de certa elite, bem como de uma tradição que, em momentos diferenciados, construíram a fisionomia cultural de São Paulo.

Assim sendo, atestando o caráter qualitativo dessa produção, concordamos com João Roberto Faria ao dizer (1998, p. 143): "Não creio que haja, na dramaturgia brasileira, outro autor que tenha aproveitado tanto quanto Jorge Andrade as experiências e vivências pessoais. O terreno em que ele se move é o mundo que traz dentro de si”.

Essas experiências, marcantes na dramaturgia andradina desde a sua primeira peça, se processam ainda hoje nas comemorações de que é alvo e nos alertam: se as novas gerações, no futuro, procurarem referências significativas que possam influenciá-las, uma das fontes dignas de credibilidade será a visão de mundo que se sustenta no teatro questionador de Jorge Andrade. Ninguém melhor que ele entendeu a História de São Paulo e a escreveu, inserindo-a em seu país. Por esse motivo, o momento de renovação não se dá apenas no que se refere à nacionalidade reivindicada num certo período, mas num contexto maior que busca nas diferenciadas leituras do país a identidade de um passado e de um presente, que mesmo depois de um tempo considerável ainda é alvo de reflexão nas encenações contemporâneas do teatro de Jorge Andrade.

Tomando como referência uma declaração do escritor, fruto do desânimo e do descrédito concedidos a ele, principalmente nos momentos finais de sua trajetória, podemos discordar, na atualidade, com certo orgulho, da voz destoante de Jorge Andrade (apud SANT’ANNA, 1997, p. 86): “ ‘o teatro brasileiro vem sendo destruído há mais de dez anos' - Jorge Andrade, 13-08-1978”. Mesmo levando em consideração o tom pessoal de tal afirmação, acreditando também no trabalho primoroso realizado por outros dramaturgos, 
conforme visto anteriormente, podemos, se olharmos com cuidado e rigor o conjunto da obra de Jorge Andrade, averiguar que o legado deixado por ele é inspirador, impactando, ainda hoje, novos atores e diretores que se valem do passado para entender o presente nas suas dimensões mais profundas, preparando o terreno para que daqui a dez anos (ou mais) olhemos para trás e enxerguemos a valiosa contribuição de Jorge Andrade.

Esse é o trabalho do historiador: cultivar terrenos, mesmo que o exercício da História se processe através da arte e desemboque no teatro a partir de experiências pessoais que se misturam às aspirações da coletividade.

\section{BIBLIOGRAFIA CITADA:}

ANDRADE, Jorge. Marta, a árvore e o relógio. 2. ed. São Paulo, Perspectiva, 1986.

ARRUDA, Maria Arminda do Nascimento. Jorge Andrade: dramaturgo de São Paulo. In: Metrópole e cultura: São Paulo no meio século XX. Bauru, EDUSC, 2001.

FARIA, João Roberto. A dramaturgia de Jorge Andrade. In: O teatro na estante. São Paulo, Ateliê Editora, 1998.

GUINSBURG, Jacó. Um teatro em rasto atrás. In: Revista da USP - Dossiê Florestan Fernandes. no. 29. maio a julho, 1996. pp. 113-5.

MAGALDI, Sábato. Panorama do teatro brasileiro. Brasília: 2a . Edição, Rio de Janeiro, SNT, 1962.

MELLO E SOUZA, Gilda. Exercícios de leitura: o baile das quatro artes. São Paulo, Duas Cidades, 1986.

NAZÁRIO, Aparecido José Carlos. Tempo e memória no teatro de Jorge Andrade: uma leitura de Rasto atrás. 1997. Dissertação (mestrado em Teoria e História Literária). Campinas, Unicamp/Instituto de Estudos da Linguagem.

PONTES, Heloísa. Intérpretes da metrópole. São Paulo, EDUSP/FAPESP, 2010.

PRADO, Décio de Almeida. Apresentaşão do teatro brasileiro moderno. São Paulo, Martins, 1956.

SANT'ANNA, Catarina. Metalinguagem e teatro: a obra de Jorge Andrade. Cuiabá, EdUFMT, 1997.

Revista do SESC - Referente ao programa da peça Vereda da salvação, encenada por Antunes Filho de dezembro de 1993 a meados de 1994.

Abstract: This paper aims to investigate some aspects of Jorge Andrade's playwriting, emphasizing, by an analysis of his most important plays, the writer's social contribution for Brazilian theater. In his plays, Jorge Andrade not only developed themes related do São Paulo's History, but also opened space in theater for the discussion of different approaches.about the country's History.

Keywords: Jorge Andrade; History; São Paulo. 